\title{
SOCIOLOGISMO' E INDIVIDUALISMO EM ÉMILE DURKHEIM
}

\author{
Sidnei Ferreira de Vares*
}

\begin{abstract}
O presente trabalho pretende analisar o tema do individualismo na teoria sociológica de Émile Durkheim com vistas a compreender a validade das críticas direcionadas por seus principais comentadores à primazia do campo social, à preocupação com a ordem e à adoção de uma postura anti-individualista que permearia toda a extensão de sua obra. Para tanto, promovemos um diálogo entre as abordagens mais recentes da obra durkheimiana e as interpretações consagradas pela tradição sociológica, com o objetivo de verificar o peso que o sociólogo francês atribuía ao indivíduo e à sociedade em sua teoria.

PALAVRAS-CHAVE: individualismo, sociologismo, crise moral, ordem, modernidade.
\end{abstract}

Émile Durkheim (1858-1917) tem sido frequentemente acusado de desenvolver uma espécie de "sociologismo", cuja principal característica seria a negação do sujeito. Sua teoria sociológica, sem dúvida herdeira do legado iluminista, principalmente no que concerne à valorização da razão humana como instrumento promotor de reformas em todos os níveis, não deixa, por um lado, de desvelar criticamente as ilusões humanistas do projeto oitocentista e, por outro, de oferecer, através da nova ciência social, formas de superar as consequentes frustrações do século das luzes. Em outros termos, a sociologia, em grande parte estimulada pelo projeto racionalista dos iluministas e sua utopia de reconstrução do mundo pela vontade humana emancipada, teve de assistir e posteriormente enfrentar o quase simultâneo fracasso dessa utopia, constituindo-se numa resposta às sucessi-

* Doutorando em Educação pela FEUSP. Professor do Centro Universitário Assuncão - UniFAI/SP e do Curso de Ciências Sociais no UniSAnt' Anna/SP

Rua Alfonso Celso, 711 - Vila Mariana - São Paulo - Brasil.vares@usp.br

${ }^{1} \mathrm{O}$ termo sociologismo, neste artigo, destaca a crítica ao holismo analítico imputado à obra de Durkheim. vas crises que acometeram a sociedade europeia. A exacerbada crença nas potencialidades da razão humana e da ciência engendrou outra crença, nesse aspecto irracional, na autorregulação do transcorrer histórico e na autorrealização da vontade humana, aquela representada pelas ideias de progresso contidas em obras como as de Spencer e Comte, e esta pelos economistas clássicos. A produção teórica de Durkheim se inscreve exatamente nesse campo conflituoso e se apresenta como crítica ao antropocentrismo radical, que situa o indivíduo como origem de tudo, ao mesmo tempo em que reafirma a possibilidade de reconstruir a sociedade francesa e europeia numa perspectiva racional. ${ }^{2}$

Todavia, as críticas empreendidas pelo sociólogo francês, em seus primeiros escritos, tanto ao sujeito da psicologia, quanto ao sujeito da filosofia, foram interpretadas num sentido declaradamente anti-individualista (Silva, 2001). Conquanto sua importância para a consolidação

${ }^{2}$ No prefácio à primeira edição de As Regras do Método Sociológico Durkheim é enfático quando declara que a única denominação teórico-filosófica que admite é a de racionalista. 
da sociologia como ciência, reconhecida nos meios acadêmicos, seja inegável, suas ideias implicam, conforme aponta uma parte de seus críticos, uma "deificação" do social e a consequente redução da ação do indivíduo, haja vista que o todo não se reduz à soma das partes e, nesse sentido, "a" sociedade, por sua anterioridade e exterioridade em relação aos membros que a compõem, colocar-se-ia naturalmente numa posição de superioridade quase ontológica. Desse ponto de vista, a sociedade constitui uma síntese das relações estabelecidas entre seus membros e, portanto, não se confunde com suas partes elementares. A perspectiva quase aristotélica adotada pelo sociólogo francês é radicalizada na medida em que a sociedade se apresenta como um ser psíquico distinto, cuja força simbólica se faz sentir sobre os seres individuais. Sendo esse ser psíquico "o mais poderoso feixe de forças físicas e morais", dele se desprende uma vida mais elevada, que reage sobre os elementos dos quais resulta. A "consciência coletiva" distingue-se dos estados de consciência individual, pois é "produto de uma imensa cooperação que se estende não apenas no espaço, mas no tempo" e que só pôde se constituir por meio de uma "multidão de espíritos diversos" que, associados, misturados e combinados em ideias e sentimentos, ao longo de gerações, intelectual e prática além dos limites instintivos. O meio social age sobre o indivíduo, modelando suas formas de agir, pensar e sentir. Disso resulta que o indivíduo, uma vez socializado, escapa dos limites impostos pela vida pré-social, mas tem seu destino encerrado pelos ditames sociais, o que validaria críticas como as de Gurvitch (1986) e Dubet (1994), que, por caminhos distintos, visualizam a sociologia durkheimiana como uma sociologia sem sujeito.

Com efeito, a observação feita por Marcel Mauss, conforme o prefácio do curso ministrado por Durkheim (1993) sobre o socialismo, publicado postumamente, de que o pensamento social desse autor poderia ser definido a partir da relação entre indivíduo e sociedade, perderia sua validade, haja vista que a primazia do social sobre o individual impede que pensemos em termos de relação. Nesse sentido, não existiria relação entre indivíduo e sociedade, mas apenas coerção do meio social sobre aquele.

Mesmo considerando que a intensificação da divisão do trabalho nas sociedades modernas implicou a substituição da "solidariedade mecânica" pela "solidariedade orgânica", dirimindo o peso exercido pelas antigas formas de organização social e alargando o campo de atuação do indivíduo, o "individualismo moral", segundo a interpretação corrente, não seria capaz de resguardar a vida coletiva, pois seu avanço constituiria uma ameaça à vida social. E mesmo sob o alerta de Durkheim de que "os velhos deuses estão mortos" e que um retorno às antigas formas de organização social seria o mesmo que negar a própria lógica da evolução histórica, a questão da "ordem" tem sido apontada como o fulcro da sociologia durkheimiana e, consequentemente, a educação reduzida a um instrumento de moralização (Fernandes, 1994).

Com o fito de compreender o peso que Durkheim atribui à sociedade e ao indivíduo, o presente artigo tem como objetivo analisar o peso exercido pelo social na construção do indivíduo, com vistas a entender o papel ocupado por esse último em sua teoria sociológica. Para tanto, faz- 
se necessário o diálogo com alguns de seus comentadores, ainda que nossa leitura se afaste das posições sustentadas pela maior parte das exposições-padrão.

\section{A PRIMAZIA DO SOCIAL: o contato com a teoria social alemã}

Existe uma polêmica instaurada entre os principais comentadores de Durkheim a respeito dos rumos tomados pelo autor no desenvolvimento de sua obra. Autores como Parsons (1968), Aron (2003) e Gurvitch (1986) apontam para uma "descontinuidade" entre os primeiros e os últimos escritos de Durkheim. Segundo essa versão, alguns conceitos básicos utilizados pelo sociólogo francês ainda na primeira fase teriam sido abandonados no decorrer de sua produção teórica. ${ }^{3}$ Esse recorte demarcaria não só o amadurecimento de Durkheim como comprovaria uma mudança de direcionamento em seus estudos, passando de uma fase "realista" para uma "idealista" ou, como preferem alguns comentadores, de uma fase estrutural para uma superestrutural (Lukes, 1984). Um segundo bloco de comentadores, entre os quais Giddens (1986, 1998, 2001), Nisbet (2003) e Ortiz (2002), falam não em uma "descontinuidade" - se por isso entendermos uma ruptura com toda a produção inicial de Durkheim -, mas em uma "reorientação" de seus estudos, uma espécie de "refinamento". Nesse sentido, as posições que identificam uma mudança repentina de orientação na obra durkheimiana, tais com a de Parsons (1968), cujo resultado é o abandono de sua produção inicial, são postas em xeque, e a tese da transição do "sociólogo" para o "antropólogo" perde sua força explicativa.

Ainda que esse debate seja prolífero para os estudiosos do mestre francês, a nós interessa

${ }^{3}$ Essa descontinuidade poderia ser facilmente constatada em conceitos como os de "solidariedade mecânica" e "solidariedade orgânica" utilizados em Da Divisão do Trabalho Social e que jamais aparecem novamente nos textos de maturidade de Durkheim. Outro exemplo, nessa mesma direção, seria a utilização tardia do conceito de "representações coletivas" para substituir o rígido conceito de "consciência coletiva", tão utilizado nos primeiros escritos. saber que a fase inicial de Durkheim foi decisiva para a estruturação de sua teoria social. Ainda como estudante de filosofia na École Normale Supérieure, entre os anos de 1879 e 1882, quando obteve o Agregé de Philosophie, Durkheim recebeu, além de sólida formação resultante da atmosfera intelectual da qual fez parte, influências diversas que incidiriam sobre sua produção teórica. Segundo Giddens (2005), durante a "fase juvenil”, Durkheim se aproximou de alguns colegas e professores no período em permaneceu na École, entre eles se destacam os professores Boutroux, Fustel de Coulanges e Renouvier e os colegas Janet e Brunot, Jaurès e Bergson, os dois primeiros da mesma turma de Durkheim e os últimos da classe imediatamente superior. Mais tarde, Durkheim tomou contato com as obras de alguns autores dos quais nunca mais pôde se afastar, tais como as de Saint-Simon, Schäffler, Wundt, Comte, Mill e Spencer. Tanto os empiristas ingleses quanto os racionalistas franceses foram determinantes para a formação intelectual de Durkheim, haja vista que "confiava na razão dentro dos limites da experiência e que acreditava na experiência segundo as regras da razão" (Fernandes, 1980, p.70). No que concerne ao método de trabalho, podemos afirmar que Durkheim se lança numa reação às propostas metodológicas indutivas apresentadas por Comte, ${ }^{4}$ visando a superar a circularidade em que seu pensamento havia sido encerrado. ${ }^{5}$ De fato, como enfatiza Augusto Santos Silva (2001, p.11), as concepções epistemológicas durkheimianas se enqua-

${ }^{4}$ Conforme explicita Florestan Fernandes: "Embora tenha aproveitado largamente várias contribuições essenciais de Comte (ideias gerais sobre a importância da indução na investigação científica e sobre o papel auxiliar das hipóteses; e certas noções bem definidas de sua teoria da investigação sociológica: em particular, que a sociologia devia ser uma ciência indutiva; que podia praticar em seu terreno de pesquisa e "experimentação indireta", além da "observação pura”; os artifícios da distinção entre o normal e o patológico; a relevância atribuída ao método comparativo e à análise causal de uniformidades de sequência), Durkheim procurou superar, de forma coerente com os princípios de investigação indutiva, a circularidade racionalista do encadeamento entre teoria e observação, inerente à concepção comtiana de explicação sociológica" (1980, p.71) [grifos do autor].

${ }^{5}$ Essa “circularidade” presente na argumentação comtiana contra a qual Durkheim reagiu, consistia em exigir para a sociologia uma teoria que ancorasse a observação dos fa- 
dram no universo gnosiológico pós-kantiano, referenciando-se principalmente pelo racionalismo científico de Comte, cujas contribuições não podem passar despercebidas. Contudo, seria tedioso e escaparia aos propósitos deste ensaio analisar pormenorizadamente todas as influências teóricas de Durkheim. ${ }^{6}$ Nossa pretensão é bem mais modesta e, conforme anunciamos, objetiva analisar as primeiras obras produzidas por Durkheim.

Após o término de seus estudos na École Normale, Durkheim trabalha em sua tese de doutoramento e leciona concomitantemente em alguns liceus interioranos e menos expressivos do que os de Paris provincianos. Nesse período, cresce seu interesse por assuntos sociais, a ponto de pedir licença em 1885 para dirigir-se à Alemanha com o propósito de estagiar no laboratório de psicologia experimental coordenado por Wundt que, nessa época, ministra um curso sobre moral. Embora curta, a estada de Durkheim em solo alemão foi decisiva para os rumos de sua obra. $\mathrm{O}$ contato com alguns autores alemães lhe fornece os pressupostos teóricos para contrapor-se à tradição espiritualista francesa e elaborar sua teoria social. Como demonstra Giddens (2005, p.111), entre os anos de 1885 e 1887, Durkheim publica alguns exames críticos nos quais analisa o pro-

tos quando a própria teoria devia resultar dessa observação. Durkheim rompe com isso ao propor, conforme sua aula inaugural em Bordeaux, que os sociólogos se beneficiem das teorias na medida em que a investigação sociológica progredir.

${ }^{6}$ Sobre as influências de Durkheim, sugerimos o texto de Lukes (1984), Émile Durkheim su vida y su obra. Vide Referências Bibliográficas. indivíduo. Conquanto reconheça que, entre os organismos vivos e as organizações sociais, existam diferenças substanciais, o autor alemão desenvolve uma morfologia social utilizando-se constantemente de analogias orgânicas, o que teria grande influência sobre os escritos de Durkheim. Em suma, o sociólogo francês endossa a ideia sustentada por aquele de que a sociedade não pode ser entendida como um mero agregado de indivíduos.

O "vanguardismo" de Schäffler propicia a Durkheim ampliar seu contato com o pensamento social alemão, levando-o a escrever uma série de artigos nos quais analisa as contribuições de outros autores como Wagner, Schmoller, Jhering e Wundt. O resultado desse intercâmbio foi o trabalho publicado em 1887 na Revue Philosophique intitulado "A Ciência Positiva da Moral Alemã", onde discorre sobre as contribuições dos autores alemães para a criação de uma ciência moral, comprovando, assim, o atraso do pensamento social francês ainda fortemente arraigado ao espiritualismo e ao utilitarismo. Grosso modo, esses autores, assim como Schäffler, opunham-se à tese dos economistas ortodoxos a respeito da autonomia das leis econômicas. Apoiados na história, os referidos autores tratam de demonstrar que a separação entre economia política e moral, tal como os economistas preconizavam, era insustentável, pois não se tratava de "dois mundos isolados, sem ligações entre si”. Sendo assim, a atividade econômica não deriva somente da ação dos indivíduos, mas da sociedade em seu conjunto. Ainda que mais tarde Durkheim tenha diminuído a importância dos autores alemães para o desenvolvimento de suas ideias, ${ }^{7}$ parece inquestionável a influência deles para sua teoria social. A dívida teórica com Schmoller pode ser facilmente constatada em $D a$ Divisão do Trabalho Social, onde Durkheim aprofunda parte das críticas que aquele autor tece aos economistas clássicos sobre a suposta inde-

${ }^{7}$ No decurso da Primeira Guerra Mundial, Durkheim, que tinha passado uma curta temporada na Alemanha, foi criticado por importar ideias de pensadores alemães. Contudo, na ocasião, rechaçou tais acusações afirmando que as ideias de Comte teriam sido mais importantes para a composição de sua teoria social do que aquelas dos autores alemães em causa. 
pendência das regras econômicas. A mesma afirmação serve para as ideias expostas por Wundt em sua Ethik a respeito dos valores morais presentes nas religiões primitivas. Mesmo considerando as influências de outras fontes teóricas, parece inegável que esses primeiros artigos críticos de Durkheim sobre os pensadores sociais alemães marcaram profundamente as diretrizes gerais de seu pensamento e, ainda que considerássemos a evolução de suas ideias, como sustentam alguns comentadores (Aron, 2003; Ortiz, 2002), a ênfase na unidade moral para a continuidade da vida coletiva e a prevalência da sociedade sobre o indivíduo demonstram que alguns pontos tratados nessa primeira fase permanecem inalterados no decurso de sua carreira intelectual.

\section{A SOCIEDADE E OS "FATOS SOCIAIS"}

As influências da primeira fase se convertem na estruturação de uma nova ciência social distinta daquela preconizada por Spencer e Comte e da qual Durkheim seria seu principal arquiteto (Ortiz, 2002). A centralidade do todo social sobre as partes que o compõem, tal como esboçaram os teóricos alemães, ganha em Durkheim sua forma mais bem acabada. O erro de Comte e Spencer teria sido o de atribuir às consciências particulares o principal fator de determinação das formas sociais, caracterizando uma abordagem psicológica refutada por Durkheim. Para o autor, "as representações, as emoções e as tendências coletivas não têm como causas geradoras certos estados de consciência individual, mas as condições em que se encontra o corpo social em seu conjunto." (Durkheim, 2001, p.67), isso porque "aqui está uma ordem de fatos que apresenta características muito especiais: consiste em maneiras de agir, de pensar e de sentir exteriores ao indivíduo, dotadas de um poder de coerção em virtude do qual se lhe impõem" (Durkheim, 2005, p.32). A generalidade, exterioridade e coercitividade são características dos fatos sociais. É como se a realidade so- cial fosse um ser psíquico distinto das consciências particulares e capaz de ultrapassá-las temporal e espacialmente, impondo-lhes certas formas de pensar, ser e agir. Essa realidade sui generis, que é a sociedade, possui uma consciência própria e independente. Como afirma, "o conjunto de crenças e dos sentimentos comuns à média dos membros de uma mesma sociedade forma um sistema determinado, que tem vida própria; podemos chamá-lo de 'consciência coletiva'.” (2008, p.50). Essa é uma ideia central para Durkheim: os fatos sociais, embora produzidos pelas relações entre os indivíduos, adquirem uma "consistência" e uma "autonomia" em relação a cada indivíduo que contribuiu para sua produção. Contudo, o autor deixa claro que a autoridade da qual está investida a sociedade é antes resultado da associação dos indivíduos.

Essa definição de sociedade trouxe muitos problemas para Durkheim. Não foram poucos os que o acusaram de desenvolver uma espécie de transcendentalismo do social. Gurvitch (1986, p.11) fala mesmo numa identificação da consciência coletiva com o "Espírito, o imperativo, a razão a priori, o Bem Supremo e, finalmente, a Divindade". Adorno (2008, p.118) afirma que Durkheim hipostasiou a sociedade com uma "realidade de segundo grau", omitindo que a sociedade é sempre composta por indivíduos e que, sem eles, sua existência seria absurda. Poderíamos citar tantos outros exemplos, contudo o que desejamos é demonstrar que a maneira como Durkheim aborda a relação entre sociedade e indivíduo, defendendo a primazia do todo sobre as partes, gerou, entre seus críticos, a impressão de que não há espaços para a ação individual em sua sociologia.

\section{DURKHEIM EA "SOCIOLOGIA DO CONSENSO"}

Em Da Divisão do Trabalho Social, Durkheim mantém muitos desses aspectos, principalmente a crítica ao individualismo utilitarista dos economistas e filósofos políticos ingleses. 
Todavia há também uma crítica, que muitos apontam como secundária, a alguns pontos nodais da teoria social comtiana, tal como a defesa de um consenso moral rigidamente definido como promotor de solidariedade social (Giddens 2005, p.117). Ao empreender uma análise dentro de moldes evolutivos sobre a solidariedade social, Durkheim desenvolve uma tipologia das organizações sociais que rompe com a rigidez da moral comtiana. As sociedades tradicionais, afirma o autor, se caracterizam por uma forte "consciência coletiva" que incide sobre seus membros e impede o desenvolvimento da individualidade. Na medida em que a divisão do trabalho nas sociedades modernas avança, a influência dos valores tradicionais tende a recuar. Esse processo pode gerar momentos de instabilidade, típicos nos períodos transitórios, que devem ser seguido por novos valores, consonantes às novas realidades engendradas. Enquanto esses novos valores não se estabelecerem plenamente, configura-se um estado de anomia. Mas que valores correspondem às necessidades das sociedades urbano-industriais? Durkheim é enfático: o "individualismo moral". Em sociedades marcadas por uma acentuada divisão do trabalho, o indivíduo dispõe de uma crescente autonomia que colide com a rigidez dos valores tradicionais. Não por acaso, Durkheim verifica que algumas instituições como a família têm sofrido profundas transformações e reduzido o poder coesivo que as caracterizava, o que the força a ver no Estado e nas corporações-profissionais, instituições capazes de regular a vida social. A moral do indivíduo seria não só adequada ao tipo de organização social moderna como também ao crescente poder de decisão do indivíduo. Como se pode perceber, essa tese, desenvolvida em Da Divisão do Trabalho Social e marginalmente em outros textos, confronta a tese comtiana sobre a necessidade de um forte consenso social (Giddens, 2005; Girola, 2005), adequada tão somente ao caso das sociedades tradicionais. Mas a forte ênfase dada ao social, já discutida noutra ocasião, leva muitos de seus críticos a enxergarem em sua tese doutoral apenas uma defesa da ordem contra a ameaça do individualismo.

Ao negligenciarem os pontos acima ressaltados, muitos comentadores acabaram por trazer a questão da ordem para o epicentro da sociologia durkheimiana. O fato de minimizarem a perspectiva evolutiva exposta por Durkheim em sua tese doutoral muito contribui para projetar o consenso moral como temática central de sua teoria (Giddens, 1998). Desse ponto de vista, a crise da sociedade industrial na viragem do século XIX é entendida como uma crise moral, e a expansão das liberdades individuais como um risco iminente à coesão social. Em decorrência, teria o sociólogo francês se lançado numa busca pela reorganização da sociedade (entenda-se moralização). Na contramão dos ideais iluministas, sua teoria social não passa de uma defesa convicta da submissão do indivíduo pelo ordenamento social, o que o aproxima, como defendem Parsons (1968), Silva (2001), Aron (2002) e Nisbet (2003), da problemática hobbesiana. Como se sabe, Hobbes, em seu Leviatã, apresenta a sociedade como resultado de um contrato estabelecido entre indivíduos isolados que, para escapar da insegurança inerente ao estado natural, firmam um pacto onde abdicam de sua liberdade natural, passando-a a um poder soberano: o do Estado. Cumpre a ele resguardar a vida de cada indivíduo, propiciando-lhe segurança, pois disso depende sua legitimidade. A tese doutoral de Durkheim constitui uma tentativa de superar as inconsistências presentes na argumentação hobbesiana, principalmente quanto ao surgimento das organizações sociais. Mesmo discordando do contratualismo de Hobbes, Durkheim, como aquele, sustenta uma posição contrária ao indivíduo, depositando no ordenamento social as expectativas de solução da crise que acomete a sociedade europeia. Com a dissolução dos laços morais tradicionais, resultante do avanço da divisão do trabalho, só o desenvolvimento de valores consistentes podem dar conta do vazio moral em que a sociedade moderna se achava mergulhada. O termo "ordem" é empregado no 
sentido de imposição de valores morais definidos. A modernidade exige uma moral racional, ainda que resguarde certos aspectos religiosos, para saciar o ímpeto dos homens.

Há uma hostilidade latente entre os homens que esta teoria [utilitarista] não explica. É como esquema de ordem que a instituição do contrato é de primordial importância. Sem ela, os homens estariam, como diz explicitamente Durkheim, em estado de guerra. Porém, a vida social efetiva não é guerra. Na medida em que implica persecução de interesses individuais, consiste que tais interesses, perseguidos de tal modo que mitiguem grandemente esta hostilidade latente, promovam a vantagem mútua e a cooperação pacifica mais que a hostilidade e destruição mútua. [...]. Está claro que o que Durkheim tem tentado é reimplantar, de forma peculiarmente vigorosa, todo o problema da ordem hobbesiano. Há traços da ordem individualista existentes que não podem ser explicados em termos dos elementos formulados na teoria utilitarista (Parsons, 1968, p.396) [tradução minha] [grifos do autor].

Esse resgate da questão hobbesiana em Durkheim pode ser avistado, como propõe Parsons (1968), no papel que ambos atribuem ao Estado. Ainda que existam diferenças, em ambos, o Estado é entendido como instituição mediadora da ordem, cujo objetivo é regular a vida dos indivíduos. ${ }^{8} \mathrm{O}$ caráter conservador de sua teoria o aproxima dos ideais conceituais de Maistre, Bonald e Chateaubriand, que fizeram parte da "revolta" contra o iluminismo. Ao discorrer sobre as principais correntes ideológicas surgidas a partir das revoluções burguesas, Nisbet (2003, p.22-23) visualiza a continuidade da ideologia conservadora na obra de Durkheim, que incorporou elementos anti-iluministas à sua rigorosa metodologia científica, conforme demonstra a antinomia entre sociedade e indivíduo. Como afirma Silva (2001, p.43-44), “a sociologia

\footnotetext{
${ }^{8}$ Nesse sentido, as críticas de Raymond Aron (2002, p. 556) sobre os riscos de deificação do Estado parecem pertinentes. Ainda que a democracia se defina para Durkheim como alargamento do diálogo entre governo e governados, nada impede que um regime nacional-socialista seja considerado democrático nos termos defendidos pelo autor. Para nós, porém, a insinuação de Aron é incapaz de dar conta da ideias políticas do sociólogo francês. Durkheim reconhecia esses riscos e empregava a noção de consciência governamental, acima de posições político-partidárias, para definir as obrigações do Estado. Ademais, os órgãos intermediários, como as corporações profissionais, são designadas a trabalhar pelo equilíbrio racional do sistema político, contrapondo-se ao poder de que o Estado dispõe.
}

durkheimiana constitui uma autêntica artilharia pesada contra o individualismo moral, que desagrega as antigas solidariedades e fez da iniciativa privada a rainha do mundo". Em Aron (2002, p.539-540), temos uma análise muito próxima das que foram expostas: assim como Hobbes, afirma Aron, Durkheim vê a sociedade como antagonista do indivíduo.

A necessidade de impor limites aos desejos dos indivíduos configura o que alguns autores (Sander, 1984; Saviani, 1995) denominaram de "sociologia do consenso". ${ }^{9}$ Como afirma (Silva, 2001, p.35), “o sociologismo de Durkheim dirige-se fundamentalmente contra o individualismo, como filosofia política e moral característica do liberalismo oitocentista”.

\section{A QUESTÃO DO INDIVIDUALISMO EM DURKHEIM}

O problema do individualismo na França remonta ao período pós-revolucionário, quando as turbulências sociais decorrentes do esfacelamento da estrutura nobiliárquica aumentam vertiginosamente. Como demonstra Lukes (1975), o caos social que se seguiu, serviu ao pensamento conservador no sentido de responsabilizar o individualismo. ${ }^{10}$ Nesse sentido, o individualis-

${ }^{9}$ Para Peter Burke, esses modelos explicativos da realidade incorrem numa simplificação dos fatos. Ainda que seu emprego seja útil no sentido de localização de um determinado sistema filosófico ou científico, os modelos explicativos tendem a negligenciar e (ou) potencializar elementos importantes do corpo teórico analisado. Conforme exemplifica Burke: “O 'modelo consensual', associado a Emile Durkheim, destaca a importância dos vínculos sociais, da solidariedade, da coesão social. O 'modelo conflituoso', relacionado com Karl Marx, dá ênfase à ubiquidade da 'contradição e do conflito social'. Ambos os modelos são simplificações, naturalmente. Também parece óbvio, pelo menos para este escritor, que os dois modelos contêm ideias importantes. É impossível encontrar uma sociedade em que não existam conflitos, do mesmo modo que, sem a existência da solidariedade, não haveria sociedade. Ainda assim, como tentarei demonstrar nas seções seguintes, não é difícil achar sociólogos e historiadores que trabalham com um, desses modelos e, aparentemente, esquecem-se do outro" (Burke, 2002, p.47-48) [grifos do autor].

10 Segundo Lukes (1975), foi Maistre o primeiro autor a empregar o termo "individualismo" com o propósito de depreciar os defensores da autonomia individual. Todavia foram os seguidores de Saint-Simon aqueles que utilizaram o termo de maneira sistemática para denunciar os perigos do individualismo para os laços sociais. 
mo pode ser tratado de dois modos, a saber: (a) como um fenômeno perverso e destrutivo dos laços sociais; (b) ou como característica do desenvolvimento da autonomia do indivíduo. $\mathrm{Na}$ França, a primeira leitura foi predominante e difundida principalmente entre os conservadores, diferentemente da segunda, que teve maior aceitação na Alemanha e na Inglaterra. Não é por acaso que Nisbet (2003) e Parsons (1968) consideram Durkheim um herdeiro da vertente conservadora. Entretanto, como sugere Girola (2005), a interpretação corrente, que opõe Durkheim aos valores iluministas, deve-se sobretudo ao desconhecimento de textos e artigos que só foram publicados muito tempo depois da morte do sociólogo francês. A partir dos anos 70 , argumenta a autora, novas pesquisas procuraram clarificar seu pensamento, e um dos pontos retomados foi exatamente o da relação entre sociedade e indivíduo. Giddens (1998), certamente, foi um dos primeiros a destacar certa confusão analítica quanto às posições de Durkheim em relação ao individualismo. Segundo o autor, as críticas de Durkheim dirigiam-se ao individualismo como método, tal como os utilitaristas defendiam, não a toda forma de individualismo. $\mathrm{O}$ artigo "O individualismo e os intelectuais", escrito por ocasião do caso Dreyfus, conteria sociedade. Nota-se claramente que a visão do autor está na contramão das concepções contratualistas e utilitaristas, o que não o impede em pensar o papel do indivíduo nas sociedades modernas. Como propõe Cladis (1992), Durkheim se esforça para sintetizar "comunitarismo" e "liberalismo", procurando superar o fatalismo daquele e o sempre presente risco do egoísmo deste. ${ }^{11}$ Mas o fato de adotar uma linguagem marcadamente sociologista, em oposição aos defensores do individualismo metodológico, gerou uma série de mal-entendidos e abriu precedentes para as interpretações convencionais. Como bem observou Alpert (1945), ao enfrentar o desafio do utilitarismo, Durkheim, infelizmente, cai numa grande armadilha, a saber, combater seus oponentes utilitaristas focando a força do social. Daí a maior parte de seus comentadores o acusarem de empreender uma "sociologia do consenso".

Como argumenta Giddens (1998, 2001), duas questões parecem contribuir para essa confusão analítica, uma decorrente da outra. Em primeiro lugar, ao negligenciarem o elemento histórico-evolutivo contido em Da Divisão do Trabalho Social, exemplificada pela passagem da solidariedade mecânica à orgânica, essas exposições-padrão, principalmente a leitura proposta por Parsons, mostram-se incapazes de compreender que, para Durkheim, a sociedade moderna, baseada na divisão do trabalho, não pode resgatar os antigos valores das sociedades tradicionais. A ampliação das liberdades individuais, assim como do próprio conhecimento racional, contraria essa percepção. Em segundo lugar, essas leituras parecem propor que o sociólogo francês se contrapôs a todo tipo de individualismo. Se, por um lado, podemos afirmar que suas críticas se direcionam ao individualismo utilitarista, por outro, a ideia de que Durkheim é contrário a todo tipo de individualismo não é correta. Sua tese vai exatamente ao encontro do "culto do indivíduo", haja vista que sociedades, com acen-

\footnotetext{
${ }^{11}$ Segundo o autor, esse esforço para sintetizar posições declaradamente díspares só pode ser entendido se considerarmos o contexto social francês do século XIX, marcado pelo sentimento de fracasso do liberalismo.
} 
tuada divisão do trabalho, só podem manter sua coesão social se o próprio indivíduo tornar-se um valor em si mesmo (Fauconnet, 1978). Essa é uma tendência da qual a modernidade não pode fugir: a suavização da "consciência coletiva" e o primado do "individualismo moral". Por mais paradoxal que isso possa nos parecer, o autor procura demonstrar, recorrendo ao método histórico, que o avanço do individualismo moral é, antes, resultado da própria evolução social (Giddens, 2005, p.117). Como afirma Ricardo Musse,

a diversidade funcional, especialização resultante do incremento da divisão do trabalho, desencadearia a emergência e o fortalecimento do 'individualismo'. Trata-se de um processo gradual de afirmação das diferenças que tem como um de seus subprodutos a "a diversidade moral" (Musse, 2007, p.7-11) [grifos do autor].

A rigidez dos valores tradicionais não condiz com as necessidades das sociedades industriais. O "culto do indivíduo" é a forma acabada de uma moral que respeita as diferenças individuais, o que não se assemelha em nada à maneira como os utilitaristas empregam o termo. Embora o risco do egoísmo seja grande, e Durkheim não o nega, aposta, contudo, na diferenciação social não forçada como um fator concernente aos novos desígnios morais da sociedade moderna, pois "a unidade do organismo é tanto maior quanto mais acentuada a individuação das partes." (Durkheim, 2008, p.108-109).

Mas esse tipo de individualismo não é aquele desregrado, defendido pelos utilitaristas. Existe uma moral que o alicerça, cujo centro é a própria pessoa humana e está acima das consciências individuais. Conforme Oliveira,

também essa sacralidade moderna, como todas as outras antigas, tem uma função social, o culto ao indivíduo é a única maneira de que uma sociedade de homens que representam funções diversas não se torne uma coleção de partes" (Oliveira, 2001, p.171).

Ainda que ressalte a legitimidade da disciplina, sua compreensão moral não descarta a deliberação. Como procurou explicitar na conclusão de tese doutoral, ao se referir à moralidade moderna, "as regras que a constituem não têm força coercitiva, que sufoca o livre exame; mas por serem muito mais feitas para nós e, em certo sentido, por nós, somos mais livres diante delas"; com isso, segundo o autor, podemos "compreendê-las e tememos menos mudá-las", haja vista que, "a tradição perdeu seu império; o juízo individual emancipou-se do juízo coletivo." (Durkheim, 2008, p.430-431).

Segundo as ideias morais expostas, principalmente em sua Educação Moral, a autonomia da vontade se apresenta como o último elemento inerente à moralidade do mundo moderno. Esse novo quesito está em consonância com o indivíduo portador da singularidade humana que desponta com a sociedade moderna. Na referida obra, Durkheim procura definir o fenômeno da moralidade e demonstrar seu caráter social, pois ela sempre remete à relação que sustentamos com os outros. O autor apresenta os três elementos constitutivos da moral, a saber: o "espírito de disciplina”, o "espírito de abnegação"12 e o "espírito de autonomia”. Os dois primeiros elementos definem a moral das sociedades simples, onde a "solidariedade mecânica" é característica. O diferencial da moral moderna está na inclusão do "espírito de autonomia", que é definido pela capacidade de o indivíduo assegurar, por meio da razão, sua adesão à regra. Alguns comentadores recentes, como Fernandes (1994), Dubet (1997) e Augusto (2009), não veem nesse novo elemento mais do que uma forma de "obediência esclarecida", sem espaço para insurgências, à medida que essa racionalidade está assentada em bases sociais ${ }^{13}$ e se apresenta objetiva e coercitivamente aos indivíduos por meio da internalização de normas e valores via educação. Assim, o indivíduo não desfrutaria de

12 Empregamos aqui a terminologia sugerida por Paul Fauconnet (1978). Todavia, Raquel Weiss (2009) fala em "espírito de adesão aos grupos" para se referir ao segundo elemento constitutivo da moralidade, segundo Durkheim.

${ }^{13}$ Em As Formas Elementares da Vida Religiosa, Durkheim, ao contrário de Kant, defende que as categorias de análise não são atributos individuais, mas sociais. Em outras palavras, a racionalidade tem um substrato social. Muitos autores veem, nessas afirmações de Durkheim, o ponto de partida para uma sociologia do conhecimento. 
uma liberdade autêntica, pois, em última instância, estaria circunscrito aos ditames sociais. Outros, porém, como Weiss (2009), Oliveira (2001) e Evangelista (1997), compreendem a autonomia da vontade num sentido mais ativo por parte do indivíduo. Eles partilham da tese de que há espaço para um julgamento moral e a consequente modificação de ideias morais consideradas antiquadas, ainda que isso dependa de um esforço coletivo e seja assessorado pelas contribuições da ciência da sociedade. ${ }^{14}$

\section{CONSIDERAÇÕES FINAIS}

Como pudemos observar, as leituras da obra de Durkheim são bastante discrepantes. Ao longo do século XX, algumas exposições-padrão, como as de Parsons, Nisbet, Gurvitch e Aron, se tornaram predominantes. Se essas interpretações enfatizam a ausência do indivíduo em sua obra, recentemente alguns comentadores, a exemplo de Giddens, Girola e Weiss, tendem a dirimir o peso do social sobre o indivíduo, apontando a racionalidade, característica do "individualismo moral”, como aquilo que certifica ao indivíduo um maior raio de ação e deliberação no meio social. Esse "culto da personalidade”, efeito do avanço da divisão do trabalho nas sociedades modernas e consonante à emergência dos ideais democráticos, é responsável por conferir ao indivíduo uma maior autonomia, principalmente no que concerne à capacidade de modificar valores sociais considerados ultrapassados a partir de esforços coletivos, visto que, isolada e dispersa, nenhuma ação individual dispõe dessa capacidade.

Todavia, não se trata de optar por esta ou aquela interpretação, pois as ambiguidades contidas nos escritos durkheimianos abrem espaço para a polêmica e impedem uma postura conclusiva a seu respeito. Conforme se verificou,

${ }^{14}$ Isso não significa que indivíduos isolados, ainda que apareçam como transgressores, também não propiciem mudanças profundas em relação aos valores sociais. O caso típico é o de Sócrates que, embora punido com a morte, modificou a moral de seu tempo. até as interpretações mais recentes comportam divergências. Por outro lado, o fato de assistirmos a uma retomada de sua obra já é, em muitos aspectos, uma conquista, principalmente se considerarmos (o que nem sempre se faz) os esforços de Durkheim para consolidar a sociologia, dando-lhe uma identidade. Com efeito, mais do que submeter a literatura especializada a um juízo de valor, o presente artigo procurou explorar as diferentes visões sobre a obra desse sociólogo clássico, explorando a polêmica e inconclusa da relação entre "sociologismo" e “individualismo".

(Recebido para publicação em 03 junho de 2010) (Aceito em 21 de dezembro de 2010)

\section{REFERÊNCIAS}

ADORNO, Theodoro. Introdução à sociologia. Trad. Wolggang Leo Maar. São Paulo: Unesp, 2008.

ALPERT, Harry. Durkheim. México: Fondo de Cultura Economica, 1945.

AUGUSTO, Maria Helena de Oliva. Indivíduo e moral em Durkheim. In: MASSELLA, Alexandre (Org.) Durkheim: 150 anos. Belo Horizonte: Argvmentvm, 2009. p.209-230.

ARON, Raymond. As etapas do pensamento sociológico. Trad. Sérgio Bath. 6.ed. São Paulo: Martins Fontes, 2003.

BURKE, Peter. História e teoria social. Trad. Klauss BrandiniGerhardt e Roneide Venâncio Majer. São Paulo: Unesp, 2002.

CLADIS, Mark. A communitarian defense of liberalism. California: Stanford University Press, 1992.

DOMINGUES, Ivan. Epistemologia das ciências humanas São Paulo: Loyola, 2004.

DUBAR, Claude. A socialização: construção das identidades sociais e profissionais. Trad. Andréa Stahel M. da Silva. São Paulo: Martins Fontes, 2005.

DUBET, François. Sociologia da experiência. Lisboa: Instituto Piaget, 1997.

DURKHEIM, Emile. Educação e sociologia. 7.ed. São Paulo: Melhoramentos, 1978. . Sociologia, educação e moral. Porto,Pt: Rés, 1984. As formas elementares da vida religiosa. Trad. Joaquim Pereira Neto. 2.ed. São Paulo: Paulus, 1989.

Socialismo. Trad. Angela Ramalho. Rio de Janeiro: Ralumé-Dumará, 1993.

et al. Introdução ao pensamento sociológico. São Paulo: Centauro, 2001. (Coletânea de textos) Lições de sociologia. Trad. Mônica Stahel. São Paulo: Martins Fontes, 2002.

Ética e sociologia moral. Trad. Paulo Castanheira. São Paulo: Landy, 2003. 
Sociologia e filosofia. Trad. Fernando Dias Andrade. São Paulo: Ícone, 2004.

As regras do método sociológico. Trad. Pietro Nassetti. São Paulo: Martin Claret, 2005.

Da divisão de trabalho social. 3.ed. Trad. Eduardo Brandão. São Paulo: Martins Fontes, 2008.

EVANGELISTA, Ely Guimarães dos Santos. Modernidade e educação em Émile Durkheim. Goiânia: EDUFG, 1997.

FAUCONNET, Paul. A obra pedagógica de Durkheim. In: DURKHEIM, Emile. Educação e sociologia. 7.ed. São Paulo: Melhoramentos, 1978.

FERNANDES, Florestan. Fundamentos empíricos da explicação sociológica. 4.ed. São Paulo: T. A. Queiroz, 1980.

FERNANDES, Heloísa Rodrigues. Sintoma social dominante e moralização infantil: um estudo sobre a educação moral em Émile Durkheim. São Paulo: Edusp/Esculta, 1994.

GIDDENS, Anthony. Durkheim. London: Fontana Press, 1986.

Política, sociologia e teoria social: encontros com o pensamento social clássico e contemporâneo. Trad. Cibele Saliba Rizek. São Paulo: Unesp, 1998.

Em defesa da sociologia: ensaios, interpretações e tréplicas. Trad. Roneide Venâncio Majer e Klauss Brandini Gerhardt. São Paulo: Unesp, 2001.

Capitalismo e moderna teoria social. Trad. Maria do Carmo Cury. 6.ed. Lisboa: Presença, 2005.

GIROLA, Lidia. Anomia e individualismo: del diagnóstico de la modernidad de Durkheim al pensamiento contemporáneo. Barcelona: Anthropos, 2005.

GURVITCH, Georges. Vocação actual da sociologia. Trad. Orlando Daniel. Lisboa: Cosmos, 1986. v. 2

LUKES, Steven. El individualismo. Barcelona: Península, 1975

Émile Durkheim su vida y su obra: estúdio histórico-crítico. Madrid: Siglo XXI de Espana, 1984.
MUSSE, Ricardo. Um diagnóstico do Mundo Moderno In: DURKHEIM, Émile. Fato social e divisão do trabalho. Apresentado e comentado por Ricardo Musse. Trad. Cilaine Alves Cunha e Laura Natal Rodrigues. São Paulo: Ática, 2007. p.7-11.

NISBET, Robert A. La formacion del pensamiento sociológico. Buenos Aires: Amorrortu, 2003. 2 v.

OLIVEIRA, Augusto César Freitas de. A modernidade e a sociologia em Emile Durkheim. Revista Comum, Rio de Janeiro, v.6. p.159-173, 2001.

ORTIZ, Renato. Durkheim: arquiteto e herói fundador. In . Texto resenha ciências sociais e trabalho intelectual. São Paulo: Olho d'Água, 2002. p.89-122.

PARSONS. Talcott. La estrutura de la accion social. Madri: Guadarrama, 1968. v.1.

PIZZORNO, Alessandro. Uma leitura atual de Durkheim. In: COHN, Gabriel (Org.) Sociologia: para ler os clássicos. Rio de Janeiro: Azougue, 2005. p.55-104.

RAMOS TORRE, Ramón. La sociologia de Émile Durkheim: patologia social, tiempo, religión. Madrid: Centro de Investigaciones Sociológicas, 1999.

SANDER, Beno. Consenso e conflito: perspectivas analíticas na pedagogia e na administração da educação. São Paulo: Pioneira, 1984

SAVIANI, Dermeval. Escola e democracia: teorias da educação, curvatura da vara, onze teses sobre educação e política. 30.ed. São Paulo: Autores Associados, 1995.

SELL, Carlos Eduardo. Sociologia clássica. 4.ed. Itajaí: Univali, 2002

SILVA, Augusto Santos. Entre a razão e o sentimento: Durkheim, Weber e a teoria das ciências sociais. 3.ed. Porto: Afrontamento, 2001.

WEISS, Raquel. A concepção de educação de Durkheim como chave para a passagem entre o positivo e normativo. In.: MASSELLA, Alexandre (Org.) Durkheim: 150 anos. Belo Horizonte: Argvmentvm, 2009. p.169-190. 


\section{SOCIOLOGY AND INDIVIDUALISM IN EMILE DURKHEIM}

\author{
Sidnei Vares
}

This paper aims to explore the theme of individualism in the sociological theory of Emile Durkheim in order to understand the validity of the criticism directed by its principal commentators to the primacy of the social field, the concern for order and the adoption of an anti-individualistic posture that pervades the full extent of his work. To this end, we promote a dialogue between the more recent approaches of Durkheim's work and the interpretations laid down by the sociological tradition, in order to check the weight that the French sociologist attributed to the individual and society in his theory.

KEYwORDS: individualism, sociologism, moral crisis, order and modernity.

\section{SOCIOLOGISME ET INDIVIDUALISME CHEZ ÉMILE DURKHEIM}

\author{
Sidnei Vares
}

Ce travail se veut d'analyser le thème de l'individualisme dans la théorie sociologique d'Émile Durkheim afin de comprendre la validité des critiques faites par ses principaux commentateurs de la primauté du champ social, de la préoccupation liée à l'ordre et à l'adoption d'une posture anti-individualiste qui traverse toute son œuvre. A cette fin, nous avons établi un dialogue entre les approches les plus récentes de l'œuvre de Durkheim et les interprétations consacrées par la tradition sociologique dans le but de vérifier l'importance que ce sociologue français a attribuée à l'individu et à la société dans sa théorie.

Mots-CLÉs: individualisme, sociologisme, crise morale, ordre, modernité.

Sidnei Ferreira de Vares - Doutorando em Educação pela FEUSP. Professor do Centro Universitário Assunção - UniFAI/SP e do Curso de Ciências Sociais no UniSAnt 'Anna/SP. Desenvolve pesquisa sobre “A Formação do Cidadão Republicano: Educação Moral e individualismo em Émile Durkheim”. Publicou, entre outros textos, o livro: "Reprodução e Resistência na Escola Capitalista: ensaios sobre sociologia da educação pela Editora Multifoco (Rio de Janeiro/ RJ) em 2010. 